\title{
Microbiological Oxidation of Steroid Hydrocarbons
}

\author{
By L. J. MULHEIRN AND J. VAN EYK* \\ Shell Biosciences Laboratory, Shell Research Ltd, Sittingbourne, Kent, U.K.
}

(Received 9 March 1981)

\begin{abstract}
Fungal and bacterial oxidation of steroid hydrocarbons has been examined. A rapid assay method for detection of metabolites derived from $5 \alpha-\left[4-{ }^{14} \mathrm{C}\right]$ cholestane is described. Out of 87 organisms tested, 16 gave isolable oxidation products, while others degraded the hydrocarbon without producing stable intermediates. Preliminary characterization of these compounds is based on chromatographic properties.
\end{abstract}

\section{INTRODUCTION}

Steroid hydrocarbons (steranes) form a significant proportion of the saturated alicyclic fraction of some crude oils and shales. The mixtures often contain $5 \alpha$-cholestane, $5 \alpha, 24 \xi$-methylcholestane and $5 \alpha, 24 \xi$-ethylcholestane, though in some instances a range of isomeric hydrocarbons has been found (Mulheirn \& Ryback, 1975). Steranes can be concentrated by distillation and can be isolated by chromatography and clathrate formation (Ryback, 1976). However, their potential as a plentiful source of steroids for conversion to pharmacologically active compounds such as progesterone and cortisone has not been exploited, largely due to the absence of methods of initial introduction of oxygen into the skeleton.

The early studies on hydroxylation and oxidation of steroidal substrates, together with recent detailed investigations by Jones and his co-workers (Bell et al., 1972a), have proved the versatility of micro-organisms, particularly fungi, in functionalizing many positions within the steroid nucleus. However, most of these processes involve molecules of the androstane or pregnane series and they are generally ineffective in steroids possessing a large C-17 side-chain (Bell et al., 1972 b).

Sterols carrying a hydroxyl group at C-3 can serve as the sole carbon source for the growth of many bacteria (Brown \& Peterson, 1966), indicating that efficient catabolic processes are indeed available in lower organisms. However, the two main pathways involve, initially, either oxidation and cleavage in ring A or hydroxylation of the C-19 methyl group, followed by aromatization of ring A. Neither pathway is likely to be applicable to steranes, which lack any oxygen atoms by which direct binding of ring $A$ to an enzyme might be achieved. A third and potentially more promising pathway of sterol catabolism in some bacteria is side-chain oxidative degradation. Oxidation of a terminal methyl group of cholesterol has been reported using Mycobacterium (Zaretskaya et al., 1968; Schubert et al., 1969; Galli-Keinle et al., 1973) and Nocardia species (Sih et al., 1968a). Subsequent side-chain breakdown appears to proceed via $\beta$-oxidation or a similar process to give $C_{27}, C_{24}$ and $\mathrm{C}_{22}$ carboxylic acids such as compound 1 (Fig. 1), with the ultimate product being a 17-oxosteroid (compound 2: Fig. 1) (Sih et al., 1968 b; Marsheck \& Karim, 1973). Isolation of the unsaturated acid, compound 3 (Fig. 1) from a Nocardia species in a related degradation sequence is consistent with the involvement of a $\beta$-oxidation pathway in this process (Sih et al., 1968b). 
<smiles>C[C@@H](CCCC(C)(C)C(=O)O)[C@H]1CCC2C3CCC4=CC(=O)CC[C@]4(C)C3CC[C@]21C</smiles>

(1)<smiles>C[C@]12CCC3C(CCC4=CC(=O)CC[C@@]43C)[C@@]1(C)CCC2=O</smiles>

(2)<smiles>C/C(C(=O)O)=C1/CCC2C3CCc4cc(O)ccc4C3CC[C@]12C</smiles>

(3)<smiles>CC(C)CCC[C@H](C)[C@H]1CC[C@H]2[C@@H]3CC[C@H]4CCCC[C@H]4[C@@H]3CC[C@@]21C</smiles>

(4)<smiles>CC(C)C1=CC(=O)OC1C(O)[C@H](C)C1CCC2C3C(=O)C=C4C[C@@H](O)CC[C@]4(C)C3CC[C@@]21C</smiles>

(5)

Fig. 1. Steroid structures referred to in the text: (1) 3-oxocholest-4-en-26-oic acid; (2) androst4-en-3,17-dione; (3) 3-hydroxy-19-norbisnorchola-1,3,5(10)-trien-22-oic acid; (4) 5a-cholestane; (5) antheridiol.

This paper reports an investigation of the potential of microbial oxidation of the sterane $5 \alpha$-cholestane (compound 4: Fig. 1) by a range of bacteria and fungi. A rapid assay method for detecting the production of more polar metabolites using $\left[4-{ }^{14} \mathrm{C}\right]$ cholestane is described. This procedure has been applied to the screening of 87 organisms under several culture conditions; 16 bacterial strains were observed to produce more polar products. Preliminary characterization of these compounds is reported.

\section{METHODS}

Sources of organisms and compounds. Most of the organisms used in this study were purchased from the National Collection of Industrial Bacteria, Aberdeen, U.K. Additional strains were obtained from the Centraalbureau voor Schimmelcultures, Baarn, The Netherlands, or from an internal reference collection of isolates. $\left[4-{ }^{14} \mathrm{C}\right]$ Cholesterol was purchased from Amersham.

Chromatographic methods. Thin-layer chromatography (t.l.c.) analytical chromatograms were run on $0.2 \mathrm{~mm}$ Merck Kieselgel $\mathrm{HF}_{254}$ plates. The chromatograms were initially developed in an unlined tank, using hexane as eluant. This resulted in elution of unchanged hydrocarbon to the solvent front while all observed metabolites were retained on the baseline. Further elution of the plates with ethyl acetate/hexane $(15: 85, \mathrm{v} / \mathrm{v})$ gave migration of metabolites other than acids to various characteristic $R_{F}$ values. Standards used included $5 a$-cholestane $\left(R_{F} 0.95\right)$, androstan-17-one $(0 \cdot 37)$, cholestanol $(0 \cdot 16)$, cholesterol $(0 \cdot 16)$, methyl cholanoate $(0 \cdot 5)$ and $5 \alpha$-cholanic acid $(0.05)$.

Radioactive chromatograms were scanned on a Desaga 12-2 plate scanner. Radioactivity of bands eluted from t.l.c. plates with ethyl acetate was measured using a Packard 3375 Tricarb liquid scintillation spectrometer. 
Samples were measured in solutions of 2,5-diphenyloxazole (PPO) plus 1,4-di-2(5-phenyloxazolyl)benzene (POPOP) in toluene or 2,5-dil 5'-tert-butylbenzoxazolyl-(2') ithiophen (BBOT) in toluene/methanol.

Growth of organisms for sterane metabolism assay. Three basic media were employed for growth of the organisms listed in Table 1. Their compositions $\left(\mathrm{g}^{-1}\right)$ were as follows.

Medium A: glucose 20, $\mathrm{KH}_{2} \mathrm{PO}_{4} 1.5, \mathrm{MgSO}_{4} .7 \mathrm{H}_{2} \mathrm{O} 1.5, \mathrm{NH}_{4} \mathrm{NO}_{3} 1.0, \mathrm{ZnSO}_{4} .7 \mathrm{H}_{2} \mathrm{O} 0.01$, L-glutamic acid 0.5 , proteose peptone $1 \cdot 0$, yeast extract 0.5 , corn steep liquor 1.0 .

Medium B: glucose $2 \cdot 5$ or 10 (see Table 1), $\mathrm{KH}_{2} \mathrm{PO}_{4} 2 \cdot 5$, yeast extract $2 \cdot 5$, Lab-lemco broth $2 \cdot 5$.

Medium C: $\mathrm{KH}_{2} \mathrm{PO}_{4} 4 \cdot 5, \mathrm{~K}_{2} \mathrm{HPO}_{4} 10 \cdot 5,\left(\mathrm{NH}_{4}\right)_{2} \mathrm{SO}_{4} 2 \cdot 0, \mathrm{MgSO}_{4} \cdot 7 \mathrm{H}_{2} \mathrm{O} 0 \cdot 1$, and trace elements solution $5 \mathrm{ml}$; $\mathrm{pH} 7 \cdot 1$. The trace elements solution contained $\left(\mathrm{g} \mathrm{I}^{-1}\right): \mathrm{MgSO}_{4} \cdot 7 \mathrm{H}_{2} \mathrm{O} 10 \cdot 0, \mathrm{MnCl}_{2} \cdot 3 \mathrm{H}_{2} \mathrm{O} 0 \cdot 1, \mathrm{FeSO}_{4} \cdot 7 \mathrm{H}_{2} \mathrm{O} 0 \cdot 4$, $\mathrm{CaCl}_{2} \mathrm{O} \cdot 1$.

Medium D, for growth of Tetrahymena pyriformis, contained $\left(\mathrm{g}^{-1}\right)$ : Bactotryptone $5 \cdot 0$, proteose peptone $5 \cdot 0$, sodium acetate $5 \cdot 0$, and $\mathrm{KH}_{2} \mathrm{PO}_{4} 1.0$ at $\mathrm{pH} 7 \cdot 1$, supplemented with a solution of $20 \%(\mathrm{w} / \mathrm{v})$ glucose $(50 \mathrm{ml})$.

Cultures were grown in $250 \mathrm{ml}$ Erlenmeyer flasks containing $50 \mathrm{ml}$ medium and an inoculum of $5 \mathrm{ml}$, and were shaken at $30^{\circ} \mathrm{C}$ for the times shown in Table 1 . In some cases dodecane or hexadecane was also added at the concentration indicated. $5 \alpha-\left[4-{ }^{14} \mathrm{ClCholestane}\left(1 \mathrm{mg} ; 2 \times 10^{5}\right.\right.$ c.p.m.) was added in 2,3,4-trimethylpentane $(0.1 \mathrm{ml})$ before sterilization. For testing of cholestane metabolism by $T$. pyriformis, dioxan was used as solvent.

Yields are quoted both on the basis of recovered material and as a percentage of added cholestane.

Assay of radioactive products from microbial incubations. Each flask was acidified to $\mathrm{pH} 1$ with concentrated $\mathrm{HCl}$ and left to stand for $30 \mathrm{~min}$. The mixture was then diluted with water and extracted four times with chloroform. The solvent was evaporated and $1 \%$ of the residue was removed for scintillation counting. The remainder of the material was analysed by t.l.c. on a $5 \times 20 \mathrm{~cm}$ silica plate. After elution in hexane the plate was dried and analysed on the scanning autoradiograph. Unchanged $5 \alpha$-cholestane appeared close to the solvent front with the metabolites at the baseline (the intensity of the metabolite radiation was often considerably reduced by absorption effects of residues on the baseline). The plate was then eluted with ethyl acetate/hexane and re-scanned for analysis of the proportions of radioactive products present. For accurate determination of the quantities of various metabolites, the active bands were scraped off and eluted with ethyl acetate, and the products were assayed by scintillation counting.

Synthesis of $5 \alpha-\left[4-{ }^{14} \mathrm{C}\right]$ cholestane. $\left[4-{ }^{14} \mathrm{C}\right]$ Cholesterol $(100 \mu \mathrm{Ci} ; 3 \cdot 7 \mathrm{MBq})$ was diluted with purified cholesterol $(200 \mathrm{mg})$ and hydrogenated over $\mathrm{PtO}_{2}(40 \mathrm{mg})$ in ethyl acetate $(20 \mathrm{ml})$ containing perchloric acid $(20 \mu \mathrm{l})$ for $1.5 \mathrm{~h}$. The catalyst was removed and the solution was washed with $1 \mathrm{M}-\mathrm{NaHCO}_{3}$. The product was crystallized from diethyl ether/methanol to give $5 \alpha$-cholestanol $(138 \mathrm{mg})$. The liquor was purified by t.l.c. with ethyl acetate/hexane $(3: 7, \mathrm{v} / \mathrm{v})$, giving coprostanol $(8 \mathrm{mg})$ and $5 \alpha$-cholestanol $(40 \mathrm{mg})$.

$5 \alpha$-Cholestanol $(178 \mathrm{mg})$ in acetone $(30 \mathrm{ml})$ was oxidized with Jones reagent and the isolated product was dissolved in toluene $(8 \mathrm{ml})$. After addition of water $(6 \mathrm{ml})$, acetyl chloride $(12 \mathrm{ml})$ and amalgamated zinc, the mixture was refluxed for $18 \mathrm{~h}$ (Enzell, 1966). The isolated product was purified by successive t.l.c. (hexane) on silica and $\mathrm{AgNO}_{3} /$ silica (10:90), which removed 2-3\% of olefinic material. The hydrocarbon was finally treated in dichloromethane $(10 \mathrm{ml})$ with $m$-chloroperbenzoic acid $(100 \mathrm{mg})$ at $20^{\circ} \mathrm{C}$ for $1 \mathrm{~h}$. The isolated product was purified by t.l.c. (hexane) to give $5 \alpha$-cholestane $\left(155 \mathrm{mg} ; 2.13 \times 10^{8}\right.$ d.p.m.; $1.37 \times 10^{6}$ d.p.m. $\left.\mathrm{mg}^{-1}\right)$. The product was stored in 2,3,4-trimethylpentane at $3 \cdot 1 \mathrm{mg} \mathrm{ml}^{-1}$ and diluted for use in metabolic studies.

\section{RESULTS AND DISCUSSION}

To explore the potential of microbial functionalization and metabolism of steranes, it was essential to employ a rapid screening technique. The method devised for this study involved addition of $5 \alpha-\left[4-{ }^{14} \mathrm{C}\right]$ cholestane to cultures, followed by t.l.c. separation and autoradiography of the recovered lipids. The method can (a) test the overall facility of the organism for cholestane metabolism under a given set of growth conditions, (b) establish the degree of conversion to more polar metabolites, and (c) provide some information on the types of metabolites produced.

Table 1 gives details of growth conditions and radioactivity recovery for 87 fungal and bacterial strains. In the Candida strains the radioactivity was located wholly in the culture fluid, while Cladosporium showed an even distribution between mycelium and the medium. In all the other fungi tested, radioactivity was located almost exclusively in the disrupted mycelium. Bacteria were not separated from the culture fluid. Acidification and chloroform extraction gave good recovery of lipids. Subsequent saponification may be valuable in some cases, since in one Corynebacterium species an increased recovery was observed with this treatment. However, in mycobacteria and other species, solvent extraction was adequate for recovery of lipids. 
Table 1. Screening of fungi, bacteria and a protozoon for metabolism of $5 \alpha-\left[4-{ }^{14} \mathrm{C}\right]$ cholestane

Strain

Cladosporium resinae

Penicillium lilaceum

Aspergillus niger

Cunninghamella blakesleeana

Candida (ex cetane)

Candida intermedia

Candida lipolytica

Nocardia A23-3‡

N. opaca

N. erythropolis

$N$. calcarea NCIB 8863

$N$. cellulans NCIB 8868

$N$. coeliaca NCIB 8939

N. globerula NCIB 9159

$N$. hvdrocarbonoxydans NCIB 9436

N. opaca NCIB 9409

N. petroleophila NCIB 9438

$N$. rugosa NCIB 8926

Nocardia NCIB 8862

Nocardia NCIB 9160

N. apis NCIB 9378

$N$. italica NCIB 9386

N. aurantiaca NCIB 9557

Corynebacterium JEIC

C. laevaniformans

C. aquaticum NCIB 9460

C. manihot NCIB 9097

C. mediolanum NCIB 7206

C. rubrum NCIB 9433

C. acetoacidophilum NCIB 9661

C. barkeri NCIB 9658

C. herculis NCIB 9694

Coryneform NCIB 9568

Coryneform NCIB 9646

Coryneform NCIB 9569

Coryneform NCIB 9647

Coryneform NCIB 9648

Coryneform NCIB 9649

Mycobacterium phlei NCIB 8573

M. phlei NCIB 8575

M. phlei CBS 49466

M. smegmatis
Glucose

Medium* $\begin{gathered}\text { Glucose } \\ \text { concn } \\ (\%)\end{gathered} \quad \begin{gathered}\text { Growth } \\ \text { period (d) }\end{gathered}$

Recovered
activity
(\%)

Conversion (\%) $\dagger$

A $\quad 2.0$

A $\quad 2.0$

A $\quad 5.0$

A $\quad 5.0$

A $\quad 5.0$

A $\quad 5.0$

A $\quad 2.0$

$\mathrm{A}^{b} \quad 2 \cdot 0$

A $\quad 2.0$

$\mathrm{A}^{b} \quad 2.0$

$\begin{array}{ll}\mathrm{A} & 2 \cdot 0 \\ \mathrm{~A}^{b} & 2.0\end{array}$

B $\quad 0.25$

$\begin{array}{ll}\mathrm{B}^{d} & 1.0\end{array}$

B $\quad 1.0$

$\begin{array}{ll}\mathrm{B}^{d} & 1.0\end{array}$

$\mathrm{B}^{d} \quad-$

B $\quad 1.0$

$\mathrm{B}^{d} \quad 1.0$

$\mathrm{B}^{d} \quad-$

B 0.25

B $\quad 0.25$

B 0.25

B $\quad 0.25$

B $\quad 0.25$

0.25

0.25

0.25

0.25

0.25

0.25

0.25

0.25

0.25

0.25

0.25

1.0

1.0

0.25

0.25

0.25

0.25

0.25

0.25

0.25

0.25

0.25

0.25

0.25

0.25

0.25

1.0

1.0

1.0

$1 \cdot 0$

1.0

1.0

1.0

1.0

0.25
89

\section{0}

65
64

52

88

\section{2}

33
96

121

101
96

89

73
22

34

84

58

61

114

94
57

111

85

86

93
23

100

88

88

101

99

73

73

82

108

71

30
84


Table 1-continued

Strain

M. rhodochrous

Arthrobacter PG§

A. globiformis NCIB 8602

A. globiformis NCIB 8605

A. tumescens NCIB 8914

A. aurescens NCIB 8912

A. citreus NCIB 8915

$A$. histidinolovorans NCIB 9541

$A$. pascens NCIB 8910

A. globiformis NCIB 8717

A. atrocyaneus NCIB 9220

A. aurescens NCIB 8912

$A$. citreus NCIB 8915

A. cystallopoietes NCIB 9499

A. duodecadis NCIB 9222

A. flavescens NCIB 9221

A. globiformis NCIB 8907

A. nicotianae NCIB 9458

A. oxydans NCIB 9333

A. pascens NCIB 8910

A. ramosus NCIB 9066

A. simplex NCIB 8929

A. tumescens NCIB 8914

A. ureafaciens NCIB 7811

A. variabilis NCIB 9455

Arthrobacter NCIB 9423

Arthrobacter NCIB 9459

A. histidinolovorans NCIB 9541

Arthrobacter NCIB 9666

Strain $\mathrm{K}_{2} \S$

Strain $\mathrm{K}_{5} \S$

Strain $\mathrm{K}_{\mathbf{4}} \S$

Strain $\mathrm{K}_{3} \S$

Strain $\mathrm{K}_{\mathbf{1}} \S$

Strain $\mathrm{K}_{\mathrm{p}} \S$

Pseudomonas 473

Strain 13(7)॥

Strain 9(7)

Strain 14(7)॥

Strain 10(7)॥

Strain 1(7)॥

Strain decalin GR

Strain 18(7)॥

Strain cholestane

Strain perhydrophenanthrene

Tetrahymena pyriformis

Medium* $\begin{array}{cc}\text { Glucose } \\ \text { concn } \\ (\%) & \text { Growth } \\ \text { period (d) }\end{array}$

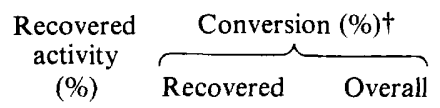

$\begin{array}{ll}\mathrm{B}^{d} & 1.0 \\ \mathrm{~B}^{6} & 1.0\end{array}$

$\mathrm{B}^{b} \quad 0.25$

$\mathrm{B}^{d} \quad 1.0$

B $\quad 0.25$

B $\quad 0.25$

B $\quad 0.25$

B $\quad 0.25$

B 0.25

B $\quad 0.25$

B $\quad 0.25$

B $\quad 0.25$

B $\quad 0.25$

B $\quad 0.25$

B $\quad 0.25$

B $\quad 0.25$

B 0.25

B $\quad 0.25$

B $\quad 0.25$

0.25

0.25

0.25

0.25

0.25

0.25

0.25

0.25

0.25

0.25

0.25

0.25

0.25

0.25

0.25

0.25

0.25

0.25

0.25

0.25

0.25

0.25

0.25

0.25

0.25

0.25

0.25

0.25

0.25

0.25

0.25

1.0
70

62
31

31
12

12
34

34
76

83

80

72

78
67

44

74
70

72

75

104

85

102

83
76

76
89

76

86

98
44

146

$<30$

80

$>80$
95

$>80$

107

67

90
78

78
79

79
92

13

13

48

85
84

84
105

66

38

34

34
46

44

29

53

90

$\begin{array}{ll}- & \\ - & <1 \\ 1 & <1 \\ <1 & < \\ - & \end{array}$

-
-
$<1$
$<1$
$<1$
-

-

$-$

$-$

$-$$$
-
$$$$
-
$$$$
-
$$$$
-
$$$$
\text { - }
$$$$
-
$$$$
-
$$$$
-
$$$$
-
$$$$
-
$$$$
-
$$$$
-
$$$$
-
$$$$
-
$$$$
-
$$$$
-
$$$$
-
$$$$
-
$$$$
-
$$$$
-
$$$$
-
$$$$
-
$$$$
<1 \quad<1
$$$$
-\quad-
$$$$
-
$$$$
\begin{array}{ll}
- & - \\
- & -
\end{array}
$$$$
\text { trace trace }
$$$$
\text { - } \quad-
$$$$
\text { - } \quad-
$$$$
\text { - }
$$$$
\begin{array}{ll}
\mathrm{B}^{b} & 0.25 \\
\mathrm{D} & 1.0
\end{array}
$$

.

\footnotetext{
* Details of the culture media are given in Methods. In some experiments dodecane or hexadecane was added to the media, as indicated by the superscripts: $a, 0.2 \%$ dodecane; $b, 0.4 \%$ dodecane; $c, 0.6 \%$ hexadecane (final concentrations, $\mathrm{v} / \mathrm{v}$ ).

$\uparrow$ The recovered conversion is based on total recovered radioactivity and the overall conversion on total added sterane.

‡ Isolated on butane. § Isolated on benzene. \# Isolated on pristane.
} 
Table 2. Cholestane metabolism by selected bacteria

\section{Organism \\ Nocardia opaca \\ $N$. erythropolis \\ N. opaca NCIB 9409 \\ Nocardia NCIB 9160 \\ N. aurantiaca NCIB 9557 \\ Corynebacterium JEIC \\ C. laevaniformans \\ Coryneform NCIB 9646 \\ Coryneform NCIB 9647 \\ Coryneform NCIB 9649 \\ Mycobacterium phlei NCIB 8573 \\ M. phlei NCIB 8575 \\ $M$. phlei CBS 49466 \\ M. smegmatis}

Arthrobacter PG॥

Strain $\mathrm{K}_{1} \|$

$\begin{array}{cccccc}\text { Conversion (\%) } & \overbrace{\text { Esters }}^{\text {Recovered }} & \text { Overall } & \text { Ketone } & \begin{array}{c}\text { Mono- } \\ \text { alcohol }\end{array} & \text { Acid, etc. } \\ 3-5 & 1-4 & ? \dagger & - & - & ++ \\ 10-12 & 5-7 & ? \dagger & - & + & ++ \\ 70 & 16 & - & + & + & +++ \\ 40 & 35 & - & ++ & + & - \\ 66 & 48 & +++ & - & - & - \\ 5-10 & 3-8 & - & ?+ & ++ & ++ \\ 5 & 2 & - & - & - & -\S \\ 33 & 20 & - & - & - & +++ \\ <5 & 4 & - & - & - & + \\ 33 & 16 & - & ? & - & +++ \\ 20 & 12 \dagger & +++ & ++ & + & + \\ 5-15 & 3-10 & +++ & ++ & + & +\ddagger \\ 50 & 14 \dagger & +++ & + & - & ++\dagger \\ 5-75 & 2-40 & ++ & + & + & ++ \\ 1 & <1 & ? & - & - & + \\ <1 & <1 \dagger & - & - & - & -\S\end{array}$

* Identified by $R_{F}$ values on t.l.c.: +++ , major metabolites; ++, significant metabolites; + , trace metabolites.

$\dagger$ Formed only in cultures lacking $n$-alkanes.

$\ddagger$ Major metabolite in presence of $n$-alkanes.

$\S$ Products not detected by autoradiography.

II Isolated on benzene.

Four fungal species and three yeast strains were screened, with no evidence of metabolite formation. With the exception of Aspergillus niger and Candida (ex cetane), efficient recovery of the hydrocarbon was obtained. The in vivo production of ergosterol and related steroids, which play a vital role in the growth and mitochondrial function of fungi, might be expected to be accompanied by rigid control of associated catabolic processes. Thus, processes of side-chain degradation are unlikely to be efficient in these organisms. Species such as Achlya, which do oxidize the sterol side-chain to produce the fungal sex hormone antheridiol (compound 5: Fig. 1) (McMorris \& Barksdale, 1967), might offer more potential for sterane metabolism.

Screening of bacteria gave more encouraging results. Of the 16 Nocardia strains examined, five gave promising levels of metabolite formation under a variety of growth conditions. Of these five strains, two strains of $N$. opaca gave low recovery of total radioactivity and little useful conversion of cholestane to polar metabolites $(\leqslant 16 \%)$. Assay results indicated that the major products were acids (Table 2). The data suggest that the low conversion results from extensive degradation of the initially formed metabolites. Nocardia erythropolis was less efficient at degrading cholestane, giving substantially higher recovery of material. Maximum observed conversion of cholestane to useful metabolites by this strain was $7 \%$ in these trials. The major products of most strains were acids, though formation of mono-alcohols and esters was also indicated. In several strains the presence of an excess of an $n$-alkane in the medium had no major influence on sterane metabolism. The use of $n$-alkane as the carbon source gave higher recoveries with no decrease in metabolite production. In later experiments, two further strains, Nocardia sp. NCIB 9160 and N. aurantiaca, also gave high recoveries (70-90\%) together with high conversion to useful metabolites (35-48\%). Significantly, strain NCIB 9160 appeared to produce compounds having the t.l.c. polarity of androstan-17-one, 


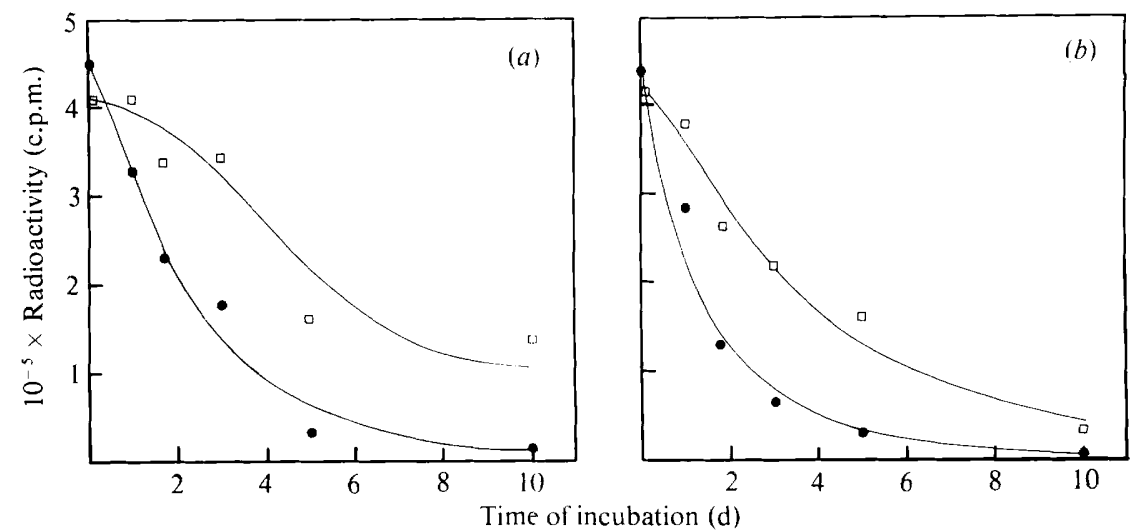

Fig. 2. Degradation of $5 \alpha-\left[4-{ }^{14} \mathrm{C}\right]$ cholestane in the presence of $\left[{ }^{3} \mathrm{H}\right]$ hexadecane by Corynebacterium JEIC grown $(a)$ on the complex medium B, and $(b)$ on the mineral medium C (see Methods). Cultures were grown in $50 \mathrm{ml}$ medium containing $0.3 \mathrm{ml}$ hexadecane and $1 \mathrm{mg} 5 \alpha$-cholestane. The curves represent the recovery of radioactive $5 \alpha$-cholestane $(\square)$ and hexadecane $(O)$ at various times during the incubations.

making this strain a suitable candidate for a further study. The products from $N$. aurantiaca appeared to be less polar.

Nine strains of Corynebacterium were examined, two of which gave promising results. The presence of $n$-alkanes had no deleterious effects on conversions in Corynebacterium strain JEIC, yields of polar metabolites being 3-8\%. In one experiment with $C$. laevaniformans, metabolites were not detected when $n$-hexadecane was incorporated, though this result was questionable since growth appeared to be retarded by the hydrocarbon. Six further coryneform bacteria were examined subsequently, three of which gave significant $(4-20 \%)$ conversion of cholestane to polar acidic metabolites. The structures of these compounds remain to be determined.

Preliminary experiments on metabolism of $5 \alpha-\left[4-{ }^{14} \mathrm{C}\right]$ cholestane by Corynebacterium strain JEIC showed that about $5 \%$ conversion to more polar compounds could be achieved under a variety of conditions, using the standard assay concentration of $20 \mathrm{mg}$ cholestane $\mathrm{l}^{-1}$. On a glucose-containing medium, products were formed without major breakdown of the steroids (Table 1). Addition of $n$-dodecane to the medium appeared to enhance both cholestane conversion to useful metabolites and the further breakdown of these metabolites. In a mineral medium supplemented with $n$-dodecane, significant oxidation was also obtained without a major increase in breakdown of the sterane or its metabolites. These results can be interpreted in terms of either an enhancement of enzyme induction by the alkane or an increased rate of absorption of the sterane by the cells in the presence of the alkane.

In a more detailed examination of the influence of aliphatic hydrocarbons on the course of cholestane breakdown, Corynebacterium strain JEIC was incubated with $5 \alpha-[4-$ ${ }^{14} \mathrm{C}$ cholestane $\left(0.67 \mathrm{mg} ; 4 \times 10^{5}\right.$ c.p.m., in $0.2 \mathrm{ml}$ iso-octane $)$ and $n$-[U- $\left.{ }^{3} \mathrm{H}\right]$ hexadecane $[0.3$ $\mathrm{ml} ; 1.9 \mu \mathrm{Ci} \mathrm{g}^{-1}\left(70 \mathrm{kBq} \mathrm{g}^{-1}\right) ; 4.5 \times 10^{5}$ c.p.m.l in both glucose-supplemented and mineral media. Breakdown of the $n$-alkane was virtually complete after $3-4 \mathrm{~d}$ in the glucose medium (medium B: Fig. 2a). Cholestane metabolism appeared to go through an initial lag phase, with significant metabolism only commencing as the $n$-hexadecane became depleted. In the mineral medium (medium $C$ ) the picture was broadly similar, though the time scale was considerably contracted, $n$-alkane breakdown being complete in $2-3 \mathrm{~d}$ (Fig. $2 b$ ). Cholestane metabolism also proceeded more rapidly, without a significant lag phase, and appeared to be maintained for a longer period, since the yield of recovered ${ }^{14} \mathrm{C}$-labelled compounds was only $7.6 \%$ after $10 \mathrm{~d}$, considerably lower than in the glucose medium. The lag phase for cholestane breakdown in the glucose-supplemented medium may reflect either preferential 
breakdown of the $n$-alkane by a common metabolic pathway such as $\beta$-oxidation or the requirement for the organism to induce a distinct set of enzymes for cholestane metabolism.

Quantitative aspects of cholestane oxidation by this organism were not encouraging. While the time-course experiments showed efficient loss of $5 \alpha$-cholestane, conversion to useful metabolites in the experiment was usually less than $5 \%$ and gave no apparent maximum. In other experiments conversions varied from $2 \%$ to $10 \%$. Increasing cholestane concentration from $20 \mathrm{mg} \mathrm{l}^{-1}$ to 200 and $400 \mathrm{mg} \mathrm{l}^{-1}$ gave significantly lower yields. This unreliable production of metabolites prevented detailed work on their structures. T.l.c. analysis of diazomethane-treated products confirmed that the predominant compounds were sterane monocarboxylic acids. Evidence for the formation of a small quantity of mono-alcohols and possibly ketones was obtained for cultures grown in the presence of $n$-alkane.

Four of the five Mycobacterium species screened proved efficient at cholestane metabolism, giving high yields of oxidized products $(2-40 \%)$. However, in contrast to the corynebacteria, the presence of liquid $n$-alkanes had a deleterious effect on metabolism, due, at least in part, to growth retardation. Detailed investigation of growth conditions and the structures of metabolites of representative strains of $M$. phlei will be reported elsewhere.

Rather surprisingly, Arthrobacter, Pseudomonas and related species, which have exceptional ability in $n$-alkane oxidation, showed little promise as practical sterane oxidizers, even in the presence of an $n$-alkane as an inducer of paraffin oxidation. From 28 Arthrobacter strains, a Pseudomonas strain and 15 related strains which had been isolated during studies on hydrocarbon oxidation, only two showed slight evidence of the formation of stable intermediates. However, the levels of recovered radioactivity were again low in 10 cases, suggesting that functionalization of the hydrocarbon may be proceeding, but only for the intermediate metabolites to undergo more efficient extended degradation. No investigations of the use of inhibitors or the potential of mutation in limiting degradation have yet been carried out.

The protozoan Tetrahymena pyriformis is capable of dehydrogenating cholesterol in both the ring system and side-chain, giving cholesta-5,7,22-trienol (Conner et al., 1969). This product is also obtained from cholest-7-en-3 $\beta$-ol and from $5 \alpha$-cholestanol (Mulheirn et al., 1971). Incubation with $5 \alpha$-cholestane, however, gave no conversion to olefinic material, indicating the necessity for the presence of a $3 \beta$-hydroxyl group for binding to the dehydrogenase enzymes.

This study shows that a large number of bacteria are capable of degrading steroid hydrocarbons such as cholestane, particularly members of the genera Nocardia, Corynebacterium and Mycobacterium. Nine strains gave overall conversions to oxidized products in excess of $10 \%$ in sub-optimal conditions. While Arthrobacter and Pseudomonas strains appear to be unable to oxidize cholestane to useful products, 11 strains gave low recovery of the hydrocarbon and may, therefore, contain active metabolic pathways whose inhibition could lead to accumulation of functionalized steroids.

\section{REFERENCES}

Bell, A. M., Denny, W. A., Jones, E. R. H., Meakins, G. D. \& Muller, W. E. $(1972 a)$. Microbiological hydroxylation of steroids, V. Journal of the Chemical Society (Perkin I), 27592765.

Bell, A. M., Cherry, K., Clark, I. M., Denny, W. A., Jones, E. R. H., Meakins, G. D. \& WoodGate, P. D. (1972b). Microbiological hydroxylation of steroids. IV. Journal of the Chemical Society (Perkin I), 2081-2095.

Brown, R. L. \& Peterson, G. E. (1966). Cholesterol oxidation by soil actinomycetes. Journal of General Microbiology 45, 441-450.
Conner, R. L., Mallory, F. B., LANDrey, J. R. \& IYENGAR, C. W. L. (1969). Conversion of cholesterol to $\Delta^{5,7,22}$-cholestatrien-3 $\beta$-ol by Tetrahymena pyriformis. Journal of Biological Chemistry 244, 2325-2333.

Enzell, C. R. (1966). Deuterium labelling by Clemmensen reduction. Tetrahedron Letters, 1285-1288.

Galli-Keinle, M., Varma, K. R., Mulheirn, L. J., YAGEN, B. \& CASPI, E. (1973). Reduction of $\Delta^{24}$ of lanosterol in the biosynthesis of cholesterol. II. Stereochemistry of addition of the C-25 proton. Journal of the American Chemical Society 95, 1996-2001. 
MCMorris, T. C. \& MARKSDAle, A. W. (1967). Isolation of a sex hormone from the water mould Achlya bisexualis. Nature, London 215, 320-321.

MARSCHECK, W. J. \& KARIM, A. (1973). Preparation of metabolites of spironolactone by microbial oxygenation. Applied Microbiology 25, 647-649.

Mulheirn, L. J. \& RYBACK, G. (1975). Stereochemistry of some steranes from geological sources. Nature, London 256, 301-302.

Mulheirn, L. J., Aberhart, D. J. \& Caspi, E. (1971). Dehydrogenation of sterols by the protozoan Tetrahymena pyriformis. Journal of Biological Chemistry 246, 6556-6559.

RYBACK, G. (1976). Chromatography of saturated steroid hydrocarbons (steranes) on alumina. Journal of Chromatography 116, 207-210.
SChubert, K., RitTer, F., SORKINA, T., BOEHME, K. H. \& HoARHOLd, C. (1969). Catabolism of steroids VIII. Journal of Steroid Biochemistry 1, 1-7.

SIH, C. J., WANG, K. C. \& TAI, H. H. (1968a). Mechanism of steroid oxidation by micro-organisms. XIII. $\mathrm{C}_{22}$ acid intermediates in the degradation of the cholesterol sidechain. Biochemistry 7, 796-807.

SiH, C. J., TAI, H. H., Lee, S. S. \& CoOmbe, R. G. $(1968 b)$. Mechanisms of steroid oxidation by microorganisms. XIV. Pathway of cholesterol sidechain degradation. Biochemistry 7, 808-818.

Zaretskaya, I. I., Kogan, L. M., Tikhomivora, O. B., Sis, J. D., WulfSON, N. S., ZARETSKII, V. I., Zaiken, V. G., Skyrabin, G. R. \& Torgov, I. V. (1968). Microbial hydroxylation of the cholesterol sidechain. Tetrahedron 24, 1595-1600. 